\title{
INFLUENCE OF INSTALLATION EFFECTS ON PILE BEARING CAPACITY IN COHESIVE SOILS - LARGE DEFORMATION ANALYSIS VIA FINITE ELEMENT METHOD
}

\author{
JAKUB KONKOL \\ Faculty of Civil and Environmental Engineering, Gdańsk University of Technology, \\ e-mail: jakub.konkol@pg.gda.pl \\ LECH BAŁACHOWSKI \\ Faculty of Civil and Environmental Engineering, Gdańsk University of Technology, \\ e-mail: abal@pg.gda.pl
}

\begin{abstract}
In this paper, the whole process of pile construction and performance during loading is modelled via large deformation finite element methods such as Coupled Eulerian Lagrangian (CEL) and Updated Lagrangian (UL). Numerical study consists of installation process, consolidation phase and following pile static load test (SLT). The Poznań site is chosen as the reference location for the numerical analysis, where series of pile SLTs have been performed in highly overconsolidated clay (OCR $\approx 12)$. The results of numerical analysis are compared with corresponding field tests and with so-called "wish-in-place" numerical model of pile, where no installation effects are taken into account. The advantages of using large deformation numerical analysis are presented and its application to the pile designing is shown.
\end{abstract}

Key words: Coupled Lagrangian Eulerian, installation effects, static load test, Updated Lagrangian

\section{INTRODUCTION}

Installation effects are general terms related to any changes of stress state, density, pore water pressure due to execution of piles, columns, sheet pile wall or densification process in the subsoil. This phenomenon is usually referred to "displacement" piles (Komurka et al. 2003) where the soil is moved outward the pile shaft. Consequently, the remoulded zone around the pile is created and the mechanical and physical parameters of the soil in pile's neighbourhood are changed. The installation effects can be divided into the following three steps (Komurka et al. 2003, Long et al. 1999): generation of the excess pore water pressure with soil structure "reorganization" during pile installation, the dissipation of the pore water pressures during consolidation phase and soil aging. From the mechanical point of view the first and second step play the most important role due to change in stress state after installation of the pile (e.g., Randolph et al. 1979). Aging of soil is problematic in description and it is ambiguous in field observation. Schmertmann (1991) reports that aging can be a relatively small part of installation effects, while Doherty and Gavin (2013) show that its effects are evident but they are spread over the years.

In this paper, the influence of installation effects on pile bearing capacity via Finite Element Method (FEM) and Abaqus software is studied. The installation effects are limited to the effective stress change during pile installation and following consolidation phase. The aging effects are omitted in the analysis due to the modelling simplification. The Poznan site is chosen as the reference location for the numerical study due to the wide range of in-situ and laboratory tests that have been performed and 16 Static Load Tests (SLT) that have been made. Two approaches are considered. In the first one, the pile installation process has been simulated and the consolidation phase has been taken into account. This pile will be referred to as a "set-up" pile in this paper. The second numerical model contains the so-called "wish-in-place" pile, where no installation effect is included and the pile is 
directly loaded up to failure. Finally, the results obtained from both numerical models are compared with field Static Load Test (SLT) conducted in Poznań site.

The main objective of this paper is to show the applicability of UL FEM in the modelling of installation effects. The comparison of SLT predictions shows the influence of the pile construction phase and the following soil consolidation on the pile's long term bearing capacity. The secondary aim of this research is to investigate which part of the pile: toe or shaft is more affected by installation effects. Finally, some remarks about observed physical changes after installation and following consolidation step are also given.

\section{GEOTECHNICAL INVESTIGATION AND PILE LOADING PROGRAM AT POZNAŃ SITE}

The three geotechnical reports have been done for the Poznań Łacina Commercial Centre located in Poznań, Poland. Totally, the in-situ investigation consists of 106 boreholes, $86 \mathrm{CPT} / \mathrm{CPT}-\mathrm{u}$ with 22 dissipation tests, 5 dilatometer tests (DMT) and 10 Dy- namic Light Probe (DPL) tests. Laboratory tests include 6 series of consolidated undrained (CU) triaxial tests, 6 oedometer tests, grain size analysis and determination of the basic physical properties. The building is founded on footings with Controlled Modulus Columns (CMC) drilled with Full Displacement Pile (FDP) auger. The SLTs contains 16 testing points in different parts of building and the $\mathrm{CMC}$ column denoted as E407 has been selected as the reference pile. The E407 column is $7 \mathrm{~m}$ long, drilled from the working platform located $3 \mathrm{~m}$ below the ground level, with pile toe buried at a depth of $10 \mathrm{~m}$. The pile considered has been selected due to very homogenous soil layer and satisfactory set of in-situ and laboratory investigation data nearby. The localization of E407 pile, neighbouring boreholes and adjacent CPT-u and DMT probing points are shown in Fig. 1. The soil profile with CPT and DMT soundings is presented in Fig. 2. The reference pile is almost entirely drilled in stiff, light grey and highly overconsolidated clay deposit $(\mathrm{OCR} \approx 12)$. The water table is recognized at a depth of approximately $0.9 \mathrm{~m}$ below ground level. The physical and typical strength parameters of Poznań clay obtained from laboratory data supplemented with CPT and DMT estimates are summarized in Table 1.

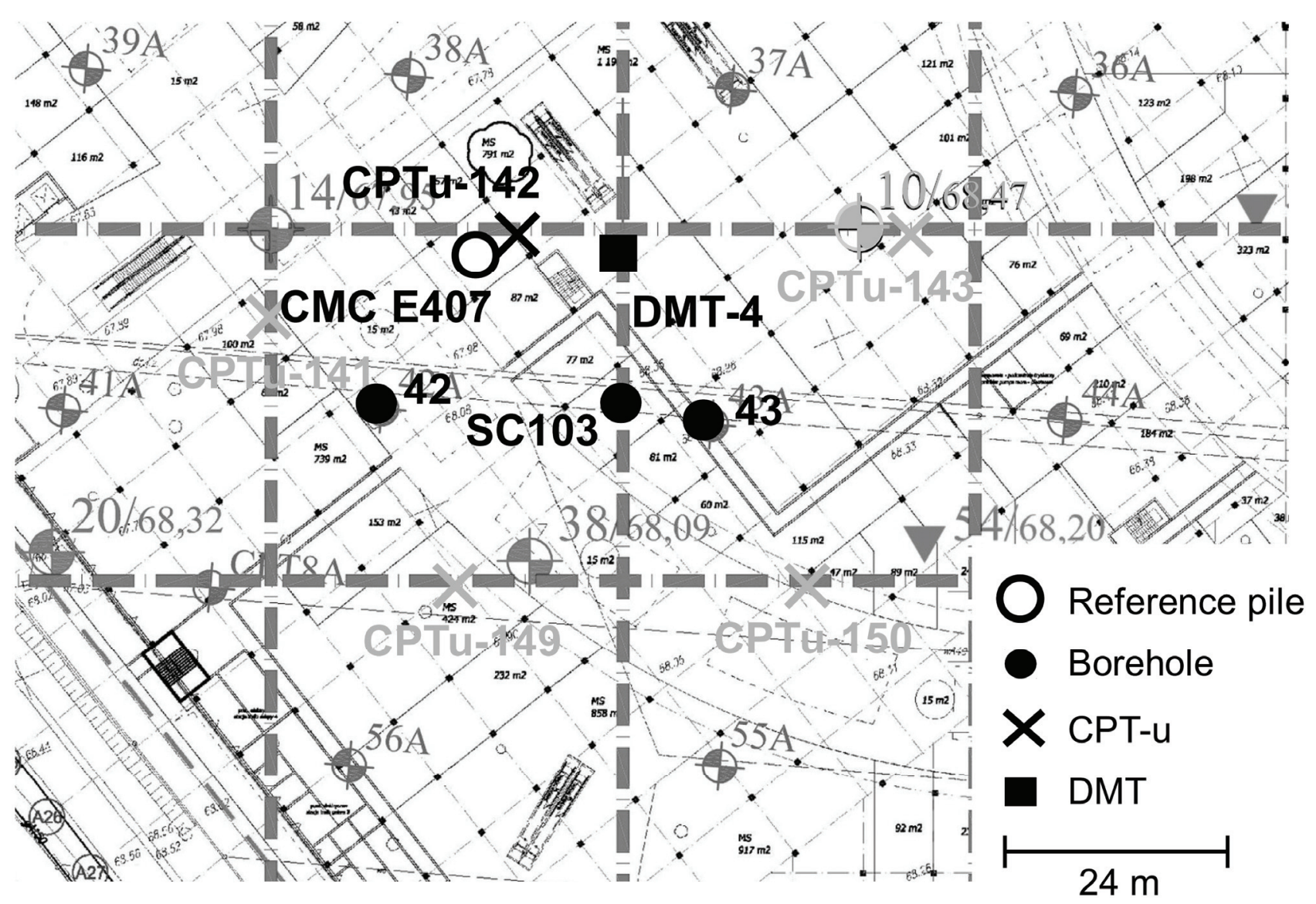

Fig. 1. Reference pile with corresponding in-situ geotechnical investigation 

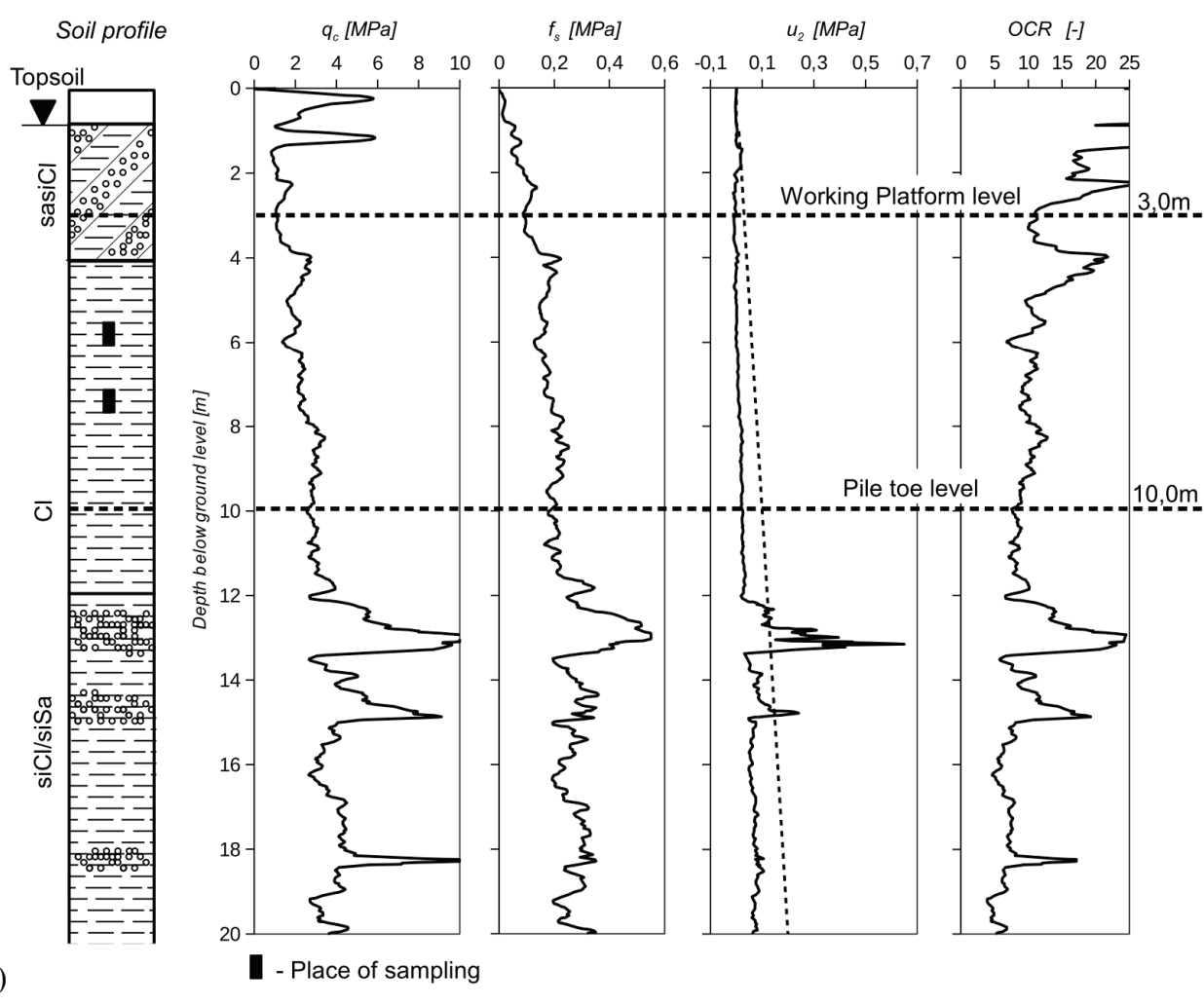

$f_{\mathrm{s}}$ [MPa]

$u_{2}[\mathrm{MPa}]$

OCR $[-]$

(a)

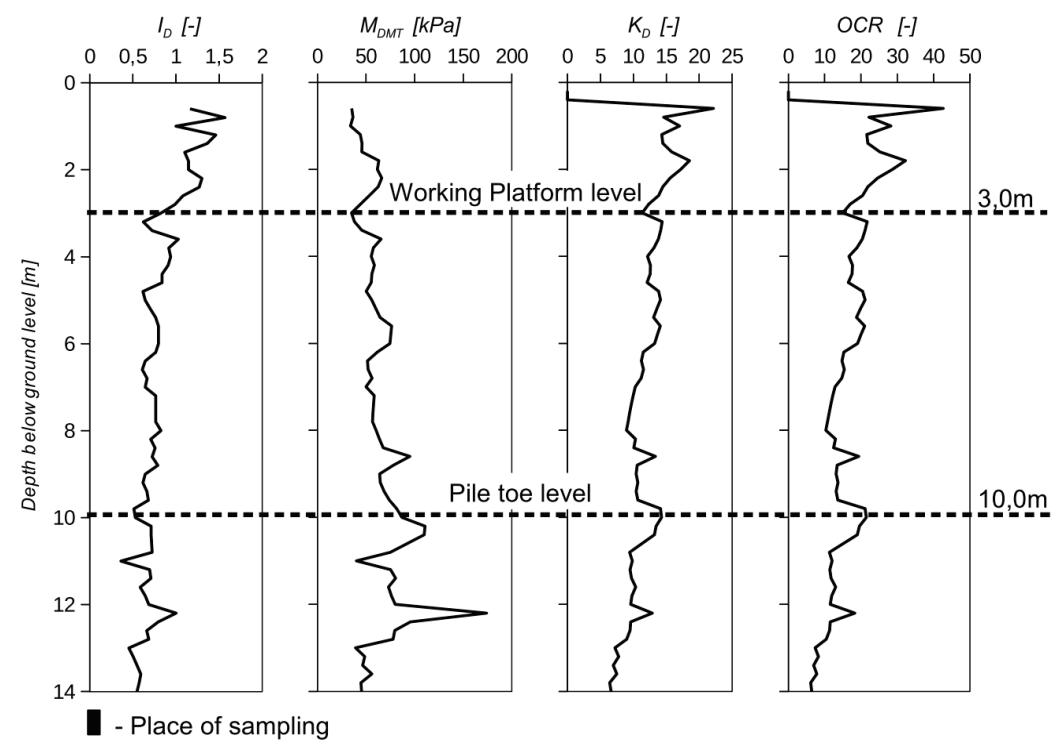

(b)

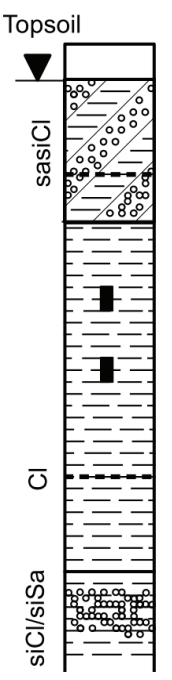

Fig. 2. (a) CPT-u 142 and (b) DMT-4 sounding results

Table 1. Poznań clay properties

\begin{tabular}{|l|l|c|c|c|}
\hline \multicolumn{2}{|c|}{ Parameter } & Notation & Value & Unit \\
\hline \multirow{4}{*}{ Physical } & Water content & $w$ & 25.7 & $\%$ \\
\cline { 2 - 5 } & Soil bulk density & $\rho_{s r}$ & 2.02 & $\mathrm{~g} / \mathrm{cm}^{3}$ \\
\cline { 2 - 5 } & Void ratio & $e_{0}$ & $0.67 \div 0.74$ & - \\
\hline \multirow{5}{*}{ Strength } & Effective angle of internal friction & $\phi^{\prime}$ & $\sim 16$ & $\circ$ \\
\cline { 2 - 5 } & Drained elastic modulus & $E^{\prime}$ & 46300 & $\mathrm{kPa}$ \\
\cline { 2 - 5 } & Undrained shear strength & $c_{u}$ & $110 \div 150$ & $\mathrm{kPa}$ \\
\cline { 2 - 5 } & Compression index & $C_{c}$ & 0.1702 & - \\
\cline { 2 - 5 } & Swell Index & $C_{s}$ & 0,0287 & - \\
\hline Permeability & Permeability coefficient & $k$ & $2 \times 10^{-12}$ & $\mathrm{~m} / \mathrm{s}$ \\
\hline Initial state & Lateral earth pressure at rest coefficient & $K_{0}$ & 2 & - \\
\hline
\end{tabular}




\section{ASSUMPTIONS AND PARAMETERS USED IN NUMERICAL MODELLING}

Modelling the installation process of CMC column via FEM remains difficult task despite recent developments in computational methods, software and hardware. However, some attempts have been made in recent years to face this issue and to better understand the influence of installation effects. An example of FDP drilling tool installation in sands was presented by Grabe et al. (2013), while Jiangtao (2009) modelled full process of sand compaction pile installation, and the same technique can also be applied to CMC columns. In Jiangtao (2009) method, the casting is jacked into the subsoil and when the design depth is reached the sand injection is lifted from the bottom boundary of the numerical model with simultaneous withdrawal of the casting. The disadvantage of this method is that only the set up effects on the pile shaft can be investigated. In this paper, the $\mathrm{CMC}$ pile installation will be treated in different way. A general assumption is that all FDP piles, independent of the technology applied, induce similar response in the soil. Consequently, similar installation effects are generated by pile driving or pile drilling as long as the FDP technology is maintained. This assumption allows for modelling a CMC column as, for instance, the jacked pile. A similar technique was used by Larisch (2014) to model screw auger displacement piles in clay. This technique does not allow for detailed modelling of prescribed CMC technology, but facilitates the problem considered and enables focusing on the stress state change around the pile after installation and the following consolidation phase. The significance of stress change around the pile due to installation has been previously shown by others (e.g., Hamann et al. 2015, Konkol and Bałachowski 2016), and it is assumed as a governing parameter of installation effects that will be considered in this paper.

The simplified CMC model will be calculated with effective stress approach using UL formulation as it is implemented in Abaqus/Standard and it will contain the entire history of E407 pile construction which includes: excavation of overlaying soil, pile installation, consolidation of the subsoil and SLT. Due to expected large distortion of the mesh in UL FEM solution the parallel and independent model with CEL formulation and Abaqus/Explicit solver will be studied. The objective of such action is the control of UL solution and possible improvement of UL FEM mesh. However, the CEL formulation implementation in Abaqus is limited to the onephase materials and thus, the CEL model will be considered in total stress approach.

The parameters used in effective stress approach with UL are derived directly from laboratory and in-situ investigation and they are shown in Table 2. The only difference appears in coefficient of permeability where the value of $k=2 \times 10^{-12} \mathrm{~m} / \mathrm{s}$ obtained from oedometer test is believed to be slightly overestimated. Consequently, the coefficient of permeability of $2 \times 10^{-10} \mathrm{~m} / \mathrm{s}$ is assumed in numerical analysis. The shear modulus is obtained from elastic drained modulus and assumed effective Poisson's ratio $v^{\prime}$ of 0.3

$$
G=\frac{E^{\prime}}{2\left(1+v^{\prime}\right)}
$$

where $G$ - shear modulus, $E^{\prime}$ - elastic drained modulus estimated from DMT (see Table 1), $v^{\prime}$ - effective Poisson's ratio.

However, a little lower shear modulus (15 MPa) in numerical analysis is assumed than provided by equation (1) ( 17 MPa). This is done to obtain $G / c_{u}$ ratio closer to typical values of large deformation
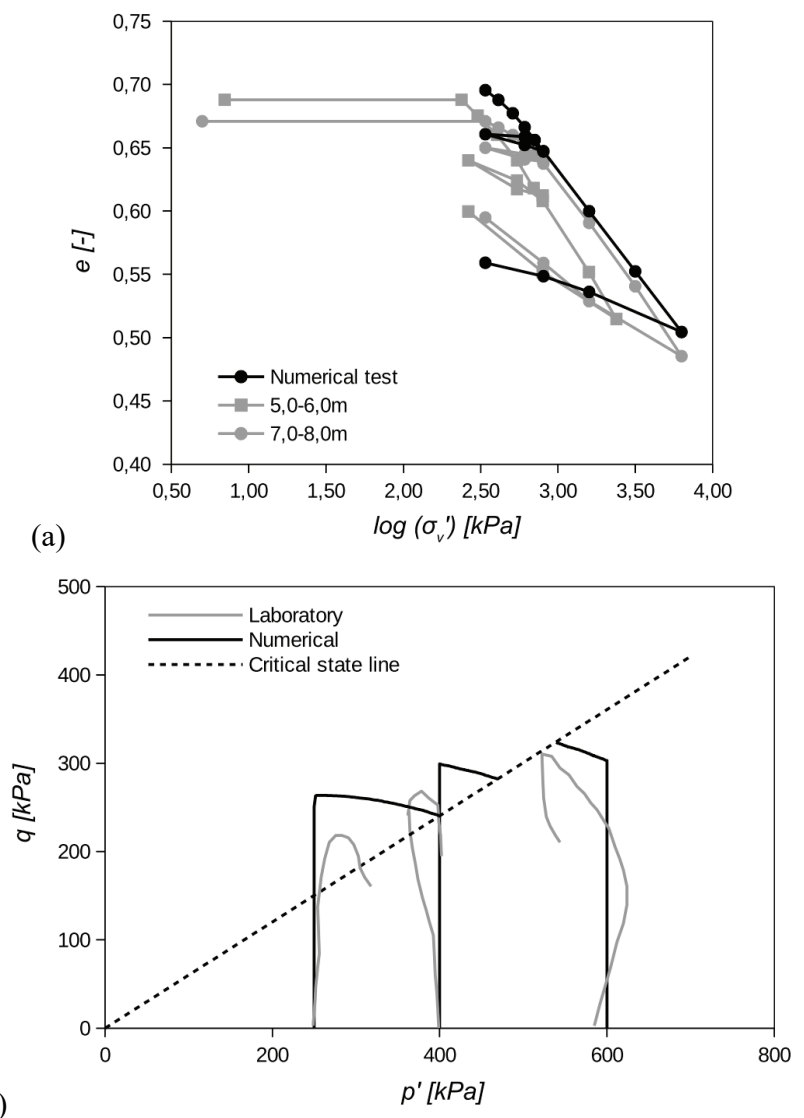

Fig. 3. Calibration of geotechnical parameters: (a) oedometer test, (b) triaxial test 
(e.g., Vardanega and Bolton 2013). The Modified Cam-Clay (MCC) model has been used as a constitutive model in numerical analysis. The parameters presented in Table 2 have been calibrated using numerical consolidated undrained (CU) triaxial and oedometer tests. The results of calibration process are shown in Fig. 3, where a very satisfactory agreement between numerical and laboratory tests has been achieved. The preconsolidation pressure used in MCC model has been selected to fullfil agreement with undrained shearing path (e.g., Worth 1984, Konkol and Bałachowski 2016):

$$
\frac{c_{u}}{p_{0}^{\prime}}=\frac{M}{2}\left(\frac{p_{c}^{\prime}}{2 p_{0}^{\prime}}\right)^{(\lambda-\kappa) / \lambda}
$$

where $c_{u}$ - undrained shear strength, $p_{0}^{\prime}$ - initial mean stress, $M-$ stress ratio, $p_{c}^{\prime}-$ preconsolidation mean stress, $\lambda$ - logarithmic plastic modulus, $\kappa$ - logarithmic elastic modulus.

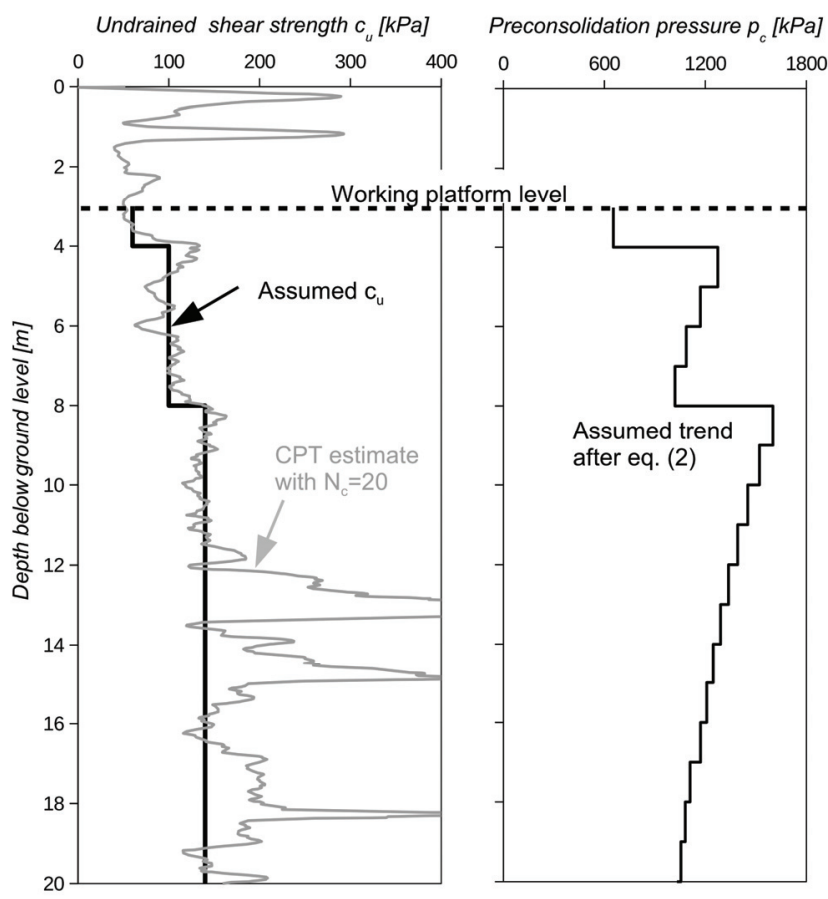

Fig. 4. Undrained shear strength and corresponding preconsolidation pressure distributions
The undrained shear strength $c_{u}$ distribution obtained from CPT assessment which was calibrated with CU triaxial test is presented in Fig. 4, where the preconsolidation pressure distribution for $1 \mathrm{~m}$ thick layers is also shown.

The total stress parameters are shown in Table 3. The undrained elastic modulus is calculated using assumption of decomposition of volumetric and shear effects (e.g., Atkinson 2007)

$$
E_{u}=2 G\left(1+v_{u}\right)
$$

where $E_{u}$ - undrained elastic modulus, $G$ - effective shear modulus, $v_{u}-$ undrained Poisson's ratio.

The undrained shear strength $c_{u}$ is adopted in numerical analysis, as shown in Fig. 4.

The most crucial parameters used in numerical solutions are those concerning the contact behaviour between pile and soil. No laboratory data concerning the interface behaviour are provided and some assessment needs to be made to find coefficients of friction. In installation phase the frictionless interaction between pile and soil is assumed. This is done due to simplification of CMC column installation. However, when SLT begins the friction behaviour between pile shaft and soil is used with coefficient of friction of 0.188 which corresponds to the angle of interface friction $\delta_{f}$ of $2 / 3 \phi^{\prime}$. This is a conservative and very safe assumption which is confirmed by various laboratory tests on soil-concrete interface (e.g., Chen et al. 2015). Using the authors' experience this estimation seems to be satisfactory due to the lack of laboratory data. The interaction between the pile toe and the soil in SLT is assumed frictionless as the only contact pressure acts on the pile base in reference field $\mathrm{CMC}$ column.

\section{THE UPDATED LAGRANGIAN MODELS}

Figure 5 presents the axisymmetric UL models. The soil domain is $11 \mathrm{~m}$ wide and $22 \mathrm{~m}$ high and due to different preconsolidation pressures it is divided

Table 2. UL model parameters with MCC model

\begin{tabular}{|c|c|c|c|c|c|c|c|c|c|}
\hline Parameter & $\rho^{\prime}\left[\mathrm{t} / \mathrm{m}^{3}\right]$ & $G[\mathrm{kPa}]$ & $e_{0}[-]$ & $\kappa[-]$ & $\lambda[-]$ & $M[-]$ & $\rho_{w}[\mathrm{kPa}]$ & $K_{0}[-]$ & $k[\mathrm{~m} / \mathrm{s}]$ \\
\hline Value & 1.02 & 15000 & 0.7 & 0.025 & 0.074 & 0.601 & 1.0 & 2.0 & $2 \times 10^{-10}$ \\
\hline
\end{tabular}

Table 3. CEL model parameters with linear elasticity and Tresca plasticity

\begin{tabular}{|c|c|c|c|c|c|}
\hline Parameter & $\rho^{\text {tot }}\left[\mathrm{t} / \mathrm{m}^{3}\right]$ & $E_{u}[\mathrm{kPa}]$ & $v_{u}[-]$ & $c_{u}[\mathrm{kPa}]$ & $\sigma_{h} / \sigma_{v}$ \\
\hline Value & 2.02 & 45000 & 0.49 & $60 \div 140$ & 1.506 \\
\hline
\end{tabular}




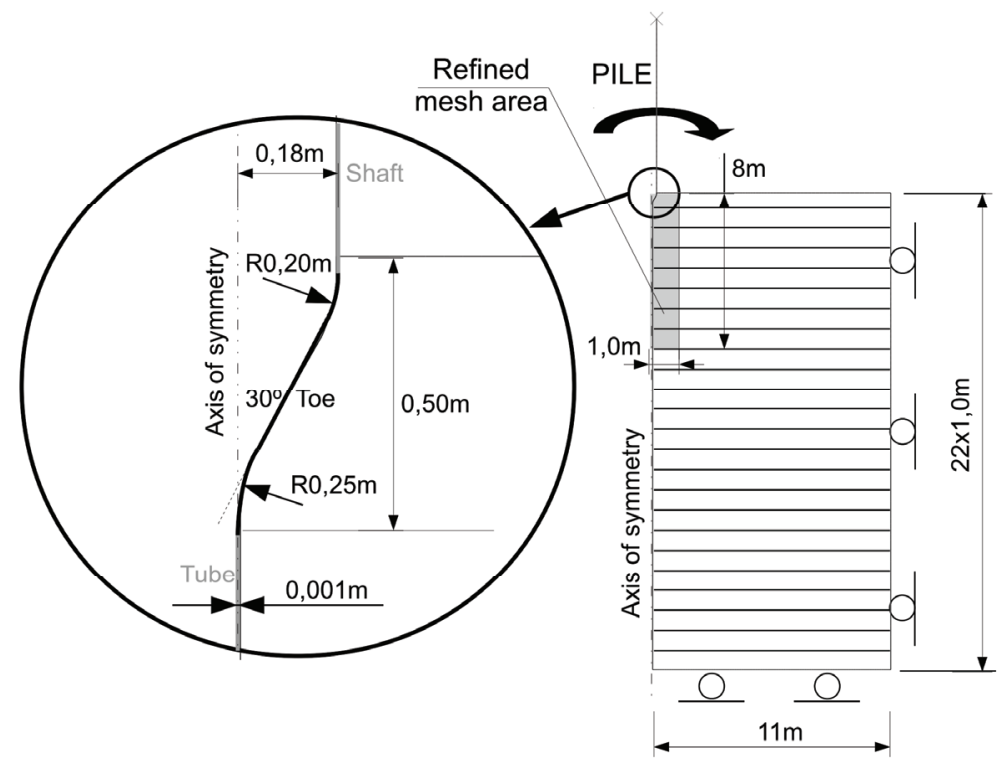

(a)

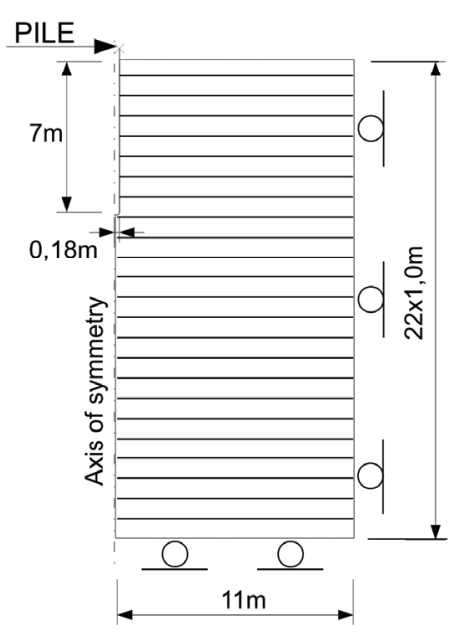

(b)

Fig. 5. Geometry of (a) CMC-1 ("set-up" pile) and (b) CMC-2 ("wish-in-place" pile) models
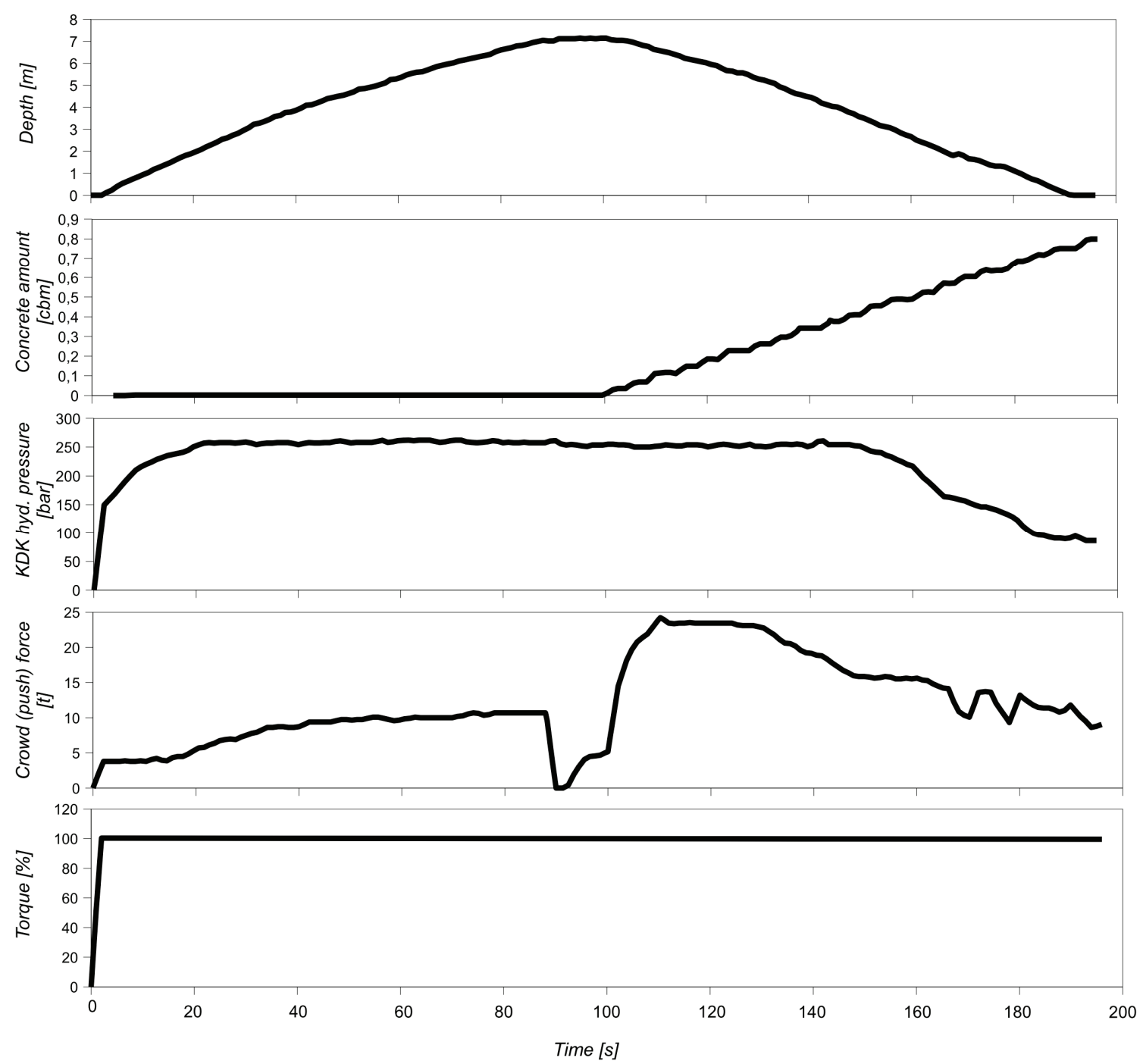

Fig. 6. CMC pile drilling log 
into 22 layers, each $1 \mathrm{~m}$ thick. The first UL model, here referred to as $\mathrm{CMC}-1$, includes subsoil and pile loading history: excavation, installation which takes place after pore water pressures equalization, 31 days of soil consolidation and finally SLT. The second UL model (CMC-2) is "wish-in-place" pile, where no installation effects are taken into account and where only SLT is modelled. Both models were discretized with quadratic, 4 nodded, linear elements with reduced integration. The $\mathrm{CMC}-1$ pile is initially preinstalled in the soil at a depth of $0.5 \mathrm{~m}$ to avoid initial severe mesh distortion (e.g., Bienen et al. 2015) and it is jacked into the subsoil with so-called zipper type technique (e.g., Mabsout and Tassoulas 1994, Konkol and Bałachowski 2016). The pile is jacked with velocity of $7 \mathrm{~cm} / \mathrm{s}$ which corresponds to the field CMC pile drilling $\log$, see Fig. 6 . The pile is modelled as a discrete rigid body.

\section{THE COUPLED EULERIAN LAGRANGIAN MODEL}

The CEL model is three dimensional due to software limitations (Dassault Systémes 2013) and its geometry is illustrated in Fig. 7. In CEL method (Noh 1963), the domain can be either Lagrangian or Eulerian one. Consequently, the soil is modelled as an Eulerian domain filled with material and it is discretized using EC3D8 elements. Lagrangian part of the model is limited to the discrete rigid pile element. The 5 finite elements per pile radius are used to obtain the optimal mesh effectiveness and this is done using the authors' experience in CEL modelling (e.g., Konkol 2015). The pile-soil contact is modelled using frictionless interaction and general contact algorithm which is based on penalty contact method.

\section{NUMERICAL RESULTS OF AFTER-INSTALLATION STATE}

A comparison between radial total stresses acting on the pile shaft after installation in UL model and CEL model is presented in Fig. 8a. As one can see, the UL solution provides overestimated values in the shaft area, but a good agreement with CEL method is obtained near pile toe. Similar effects can be seen in papers presented by Qiu et al. (2011) and Hamann

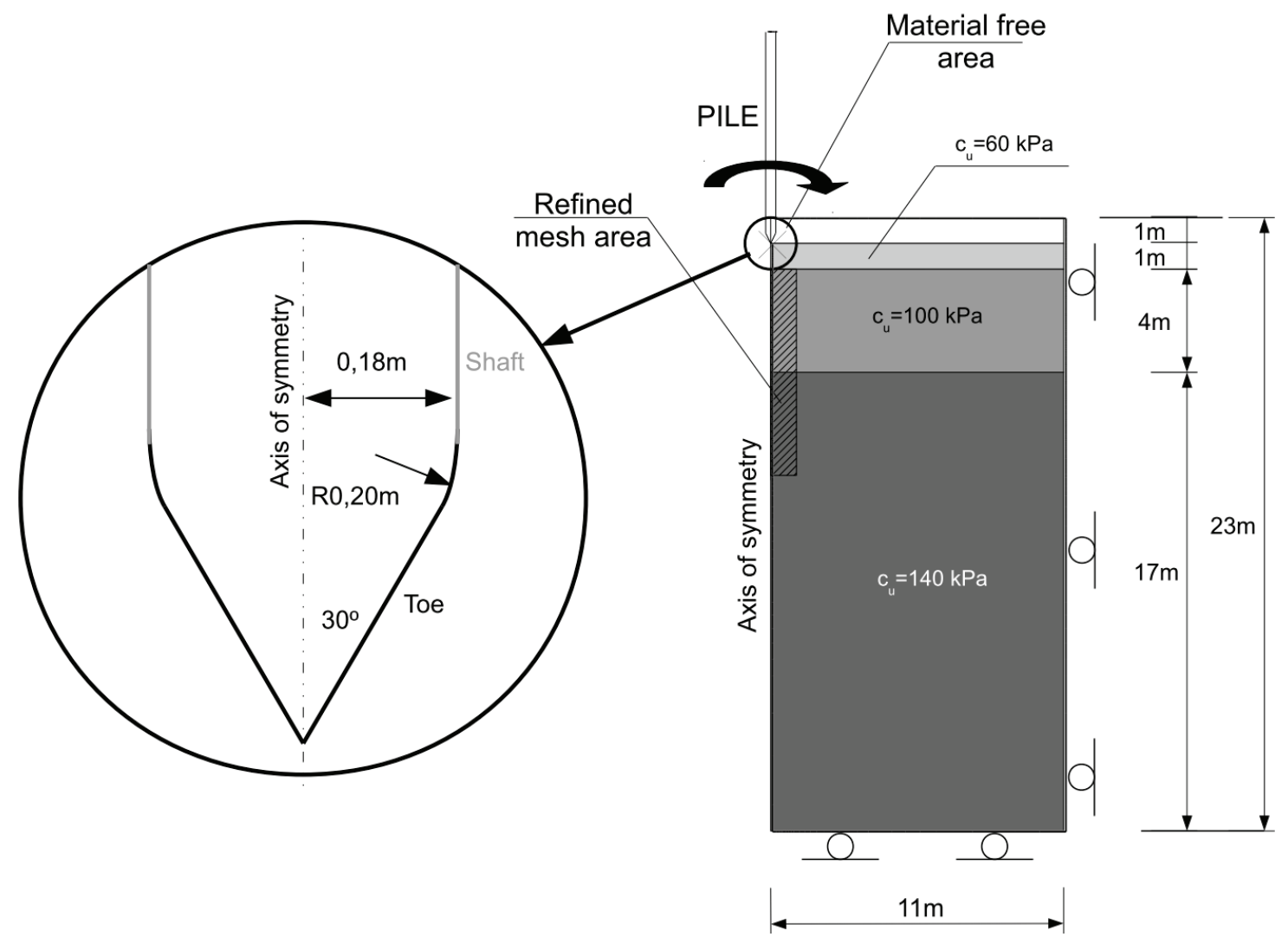

Fig. 7. CEL numerical model geometry 


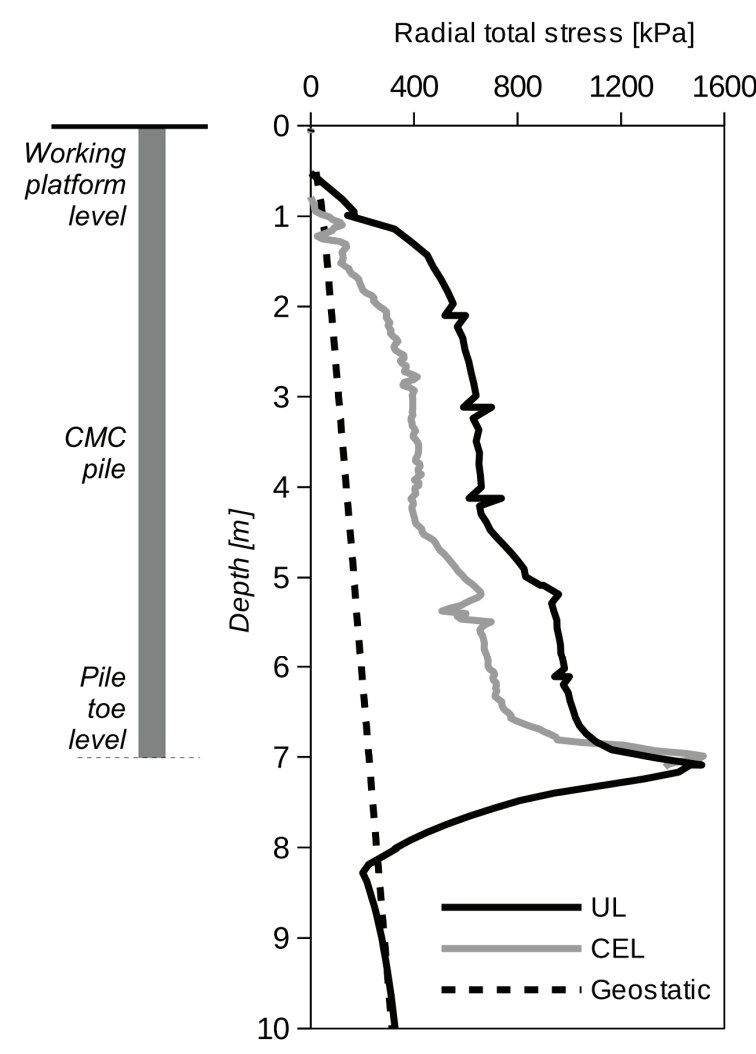

(a)

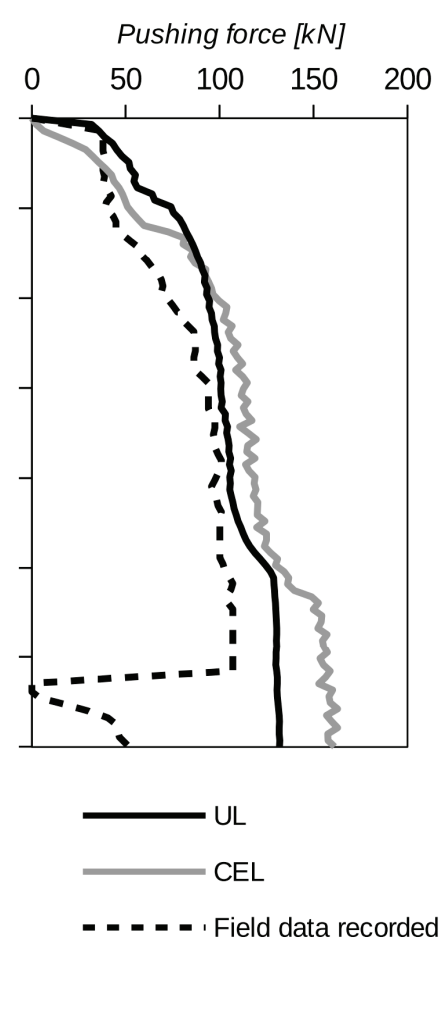

(b)

Fig. 8. (a) Radial total stress acting on the pile wall after installation,

(b) total pushing force obtained from numerical analysis and field drilling log

et al. (2015), where also CEL method provides lower values of radial stress than corresponding UL FEM method. It is worth noting that rapid decreases in CEL radial stress distribution are usually seen at material layer boundaries, i.e., at a depth of $1 \mathrm{~m}$ (change between $c_{u}=60 \mathrm{kPa}$ and $\left.c_{u}=100 \mathrm{kPa}\right)$ and at a depth of $4 \mathrm{~m}$ (change between $c_{u}=100 \mathrm{kPa}$ and $c_{u}=140 \mathrm{kPa}$ ). The total resistance force which acts on the pile is compared with drilling pushing force in Fig. 8b. This kind of comparison is not exactly proper due to the slightly different failure mechanisms. Figure $8 \mathrm{~b}$ shows that both numerical models give similar response in comparison with the data from drilling machine. Consequently, both numerical models can be treated as a good approximation of the phenomenon during CMC column installation.

\section{NUMERICAL RESULTS OF AFTER-CONSOLIDATION STATE}

The pore pressure distribution after consolidation phase is presented in Fig. 9a. As can be seen, the positive excess pore water pressures have been developed along significant pile length and the largest ones are concentrated around the pile toe. The dissipation curves for 31 day period between installation and SLT are shown in Fig. 9b. The basic part of excess pore water pressure dissipates during the first 10 days after pile construction. After 31 days the pore water pressures in the lower part of the pile are almost equalized, but in the upper part the negative pore water pressure can still be observed, see Fig. 10. Figure 10 also shows a significant radial effective stress increase after installation and 31 days of consolidation. The physical changes induced by installation and subsequent consolidation are illustrated in Fig. 11. The soil movement (Fig. 11a) due to pile installation is complex and can be interpreted as a combination of the horizontal and vertical displacements. Here, the basic advantage of UL method in comparison with the Cavity Expansion Method (CEM) can be seen. In CEM only the horizontal component of displacement is taken into account (e.g., Randolph et al. 1979). The decrease of void ratio can be noted especially around the pile toe, see Fig. 11b, while some sort of increase can be observed near the surface area. 


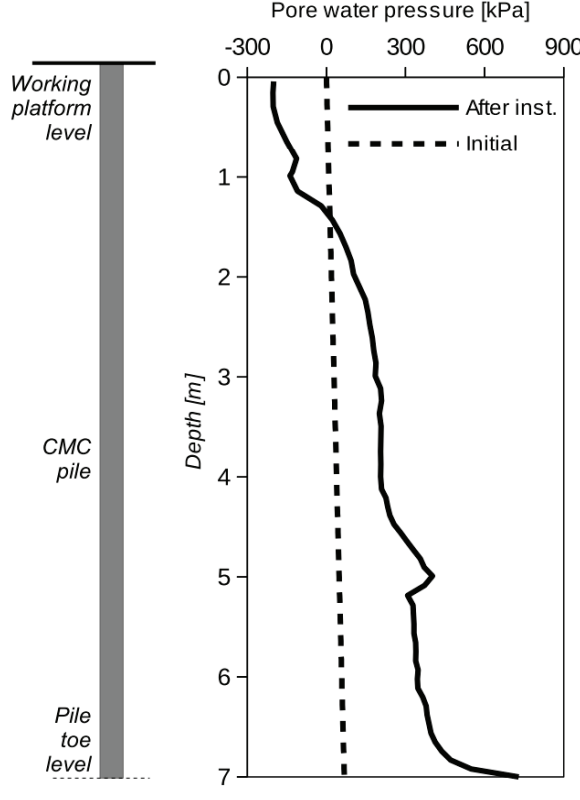

(a)
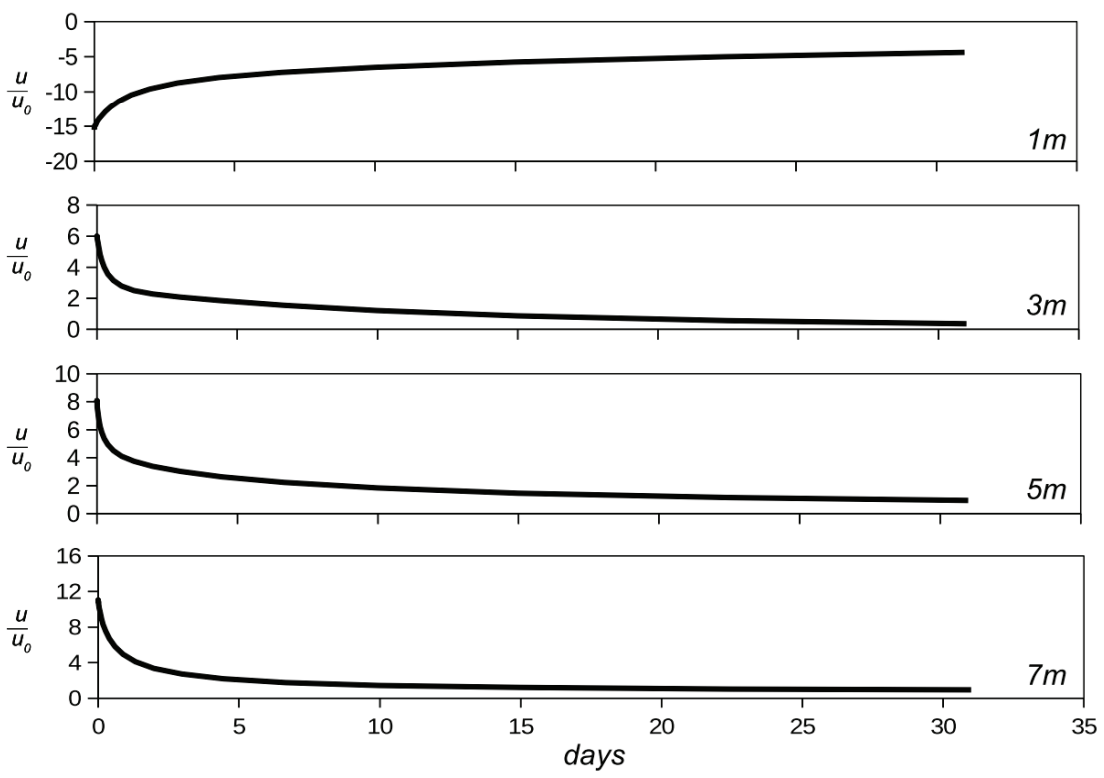

(b)

Fig. 9. (a) Pore water pressure distribution along pile wall after installation, (b) dissipation curves for selected depths
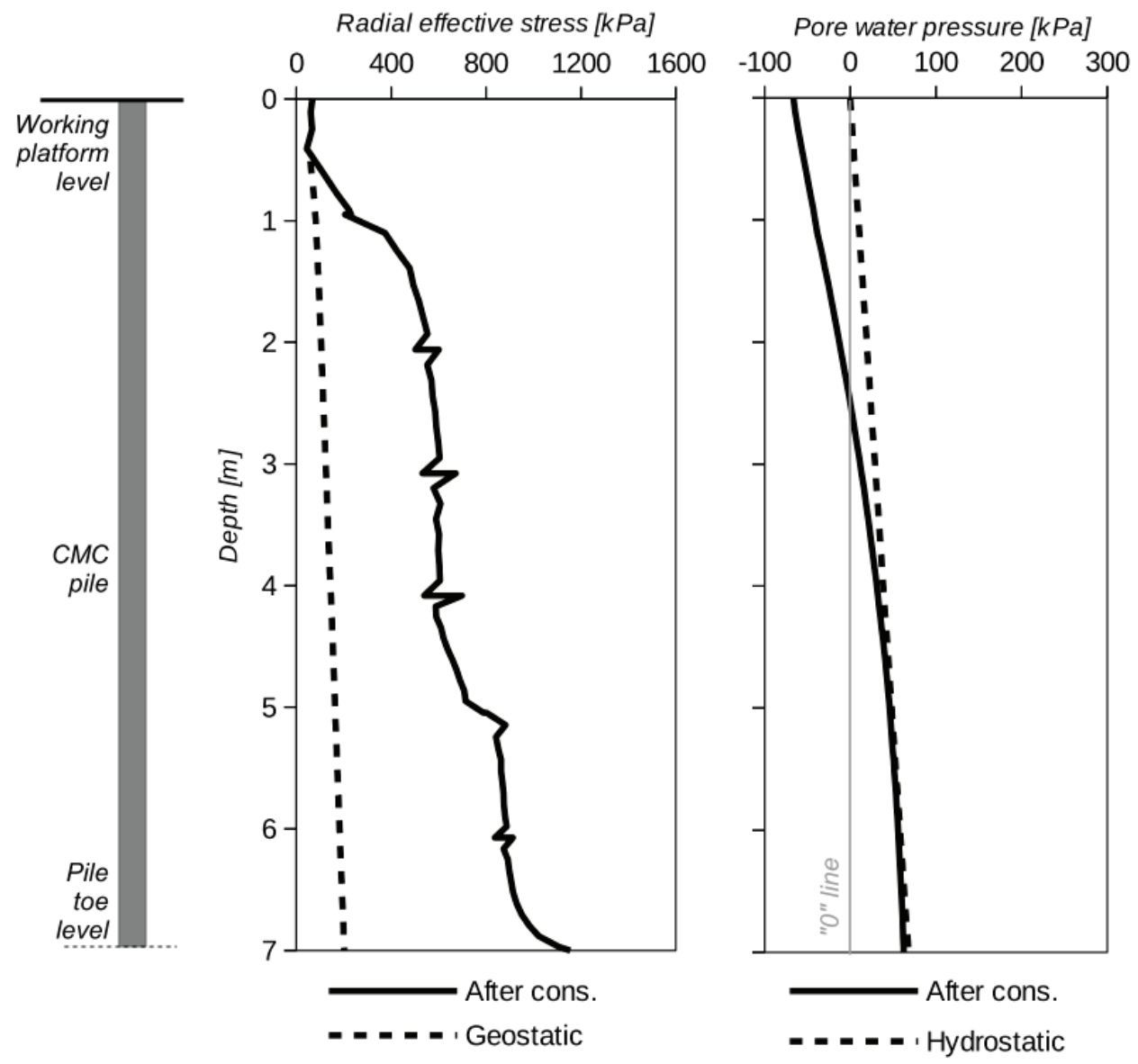

Fig. 10. Radial effective stress and pore water pressure distributions along pile wall after 31 days of consolidation 


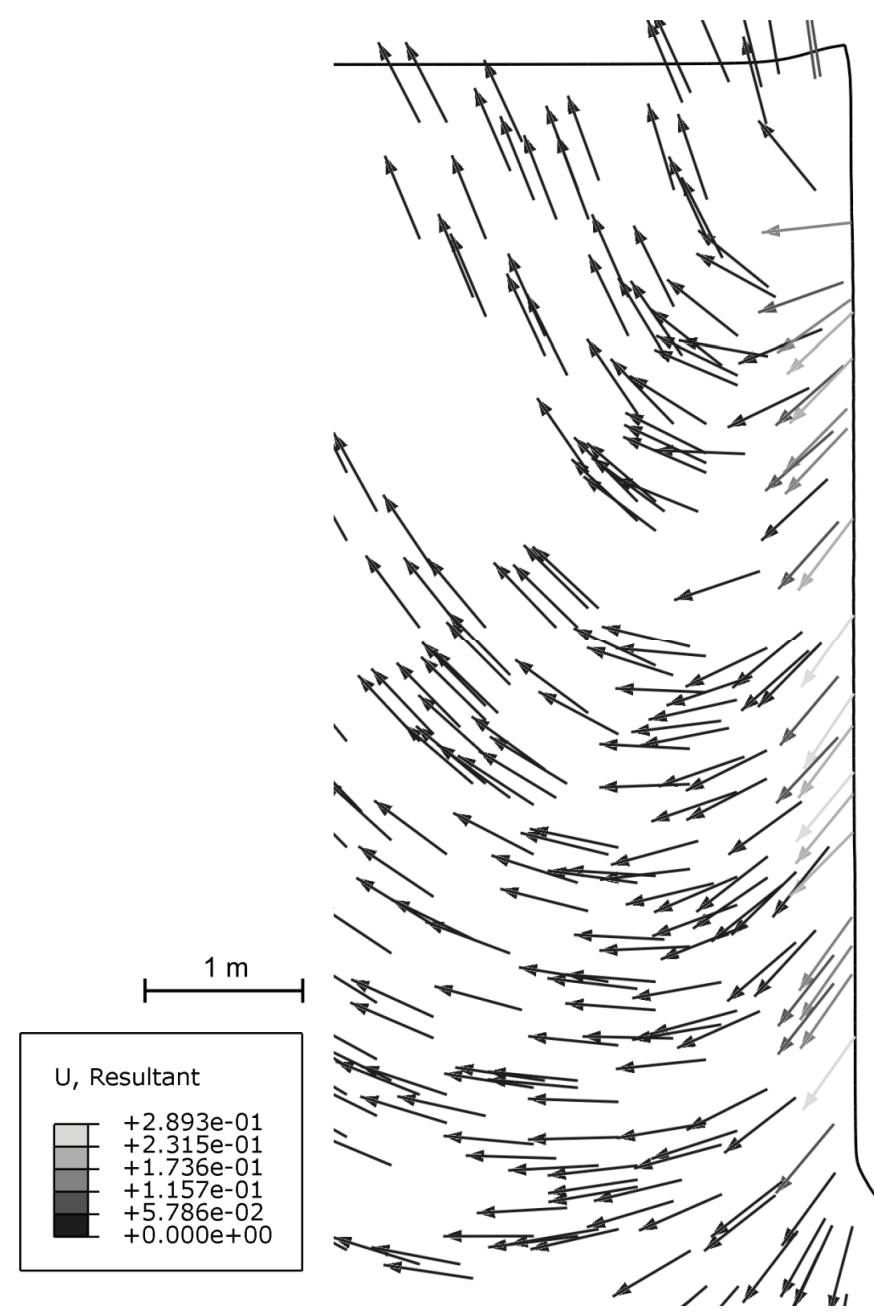

(a)

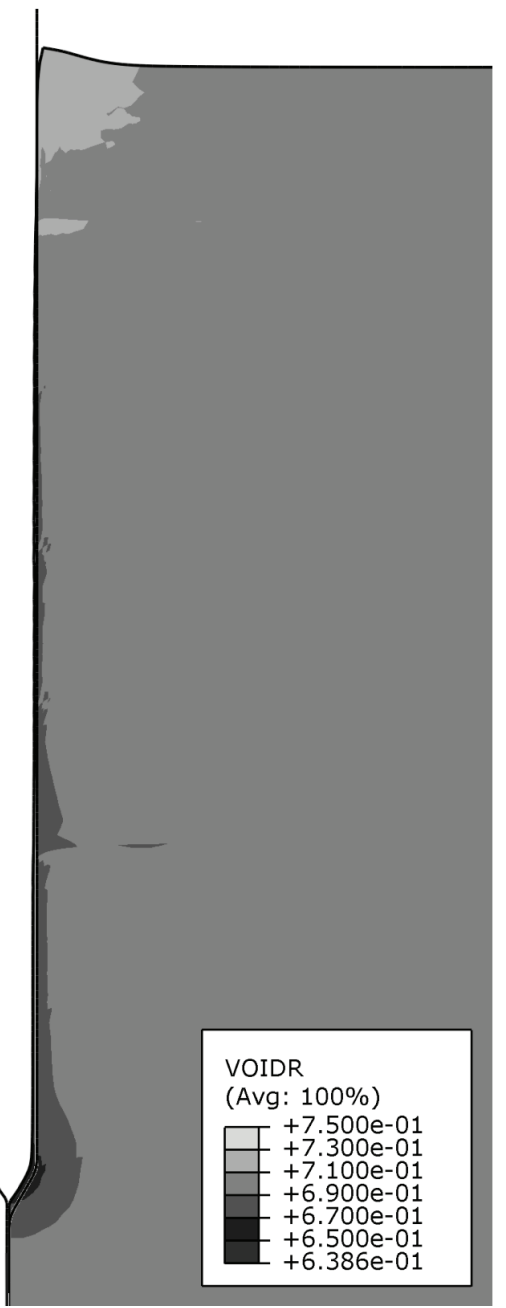

(b)

Fig. 11. (a) Displacement of soil around the pile and (b) void ratio change at the end of installation and consolidation phase

\section{STATIC LOAD TEST - NUMERICAL ANALYSIS VERSUS FIELD MEASUREMENTS}

The field SLT results compared with the UL solution for CMC-1 and CMC-2 are presented in Fig. 12. The CMC-1 model, where full installation process has been modelled, gives almost perfect fit to the filed data. The pile bearing capacity CMC-2 is almost 3.5 times lower due to the lack of the installation effects. Figure 13 shows the decomposition of the total pile bearing capacity obtained in numerical analysis into shaft and pile toe capacities. The total toe capacity is similar irrespective of installation effects. Further, it is almost equal to the well-known empirical formula for pile toe capacity (e.g., Tomlinson and Woodward 2014)

$$
Q_{b}=9 c_{u} A_{b}
$$

where $Q_{b}$ - pile base capacity, $c_{u}$ - undrained shear strength, $A_{b}$ - pile base area.

Substituting $c_{u}$ of $140 \mathrm{kPa}$ and the base area of $0.102 \mathrm{~m}^{2}$ for $0.36 \mathrm{~m}$ diameter of CMC column, the base capacity can be calculated as equal to $128.5 \mathrm{kN}$, which is very similar to numerical results.

A totally different observation can be made in relation to the shaft capacity. The set up effects increase the shaft capacity more than 7 times in comparison with the "wish-in-place" pile. This is a consequence of radial stress state change due to pile installation. The average initial radial effective stress along the pile shaft is $72.8 \mathrm{kPa}$, while after installation and following consolidation phase this value increases to $605 \mathrm{kPa}$. As a result, almost 8 times increase in average radial effective stress is noted and it can be interpreted as a direct reason for the pile shaft capacity increase, see Fig. 11. Consequently, due to the large influence of installation 


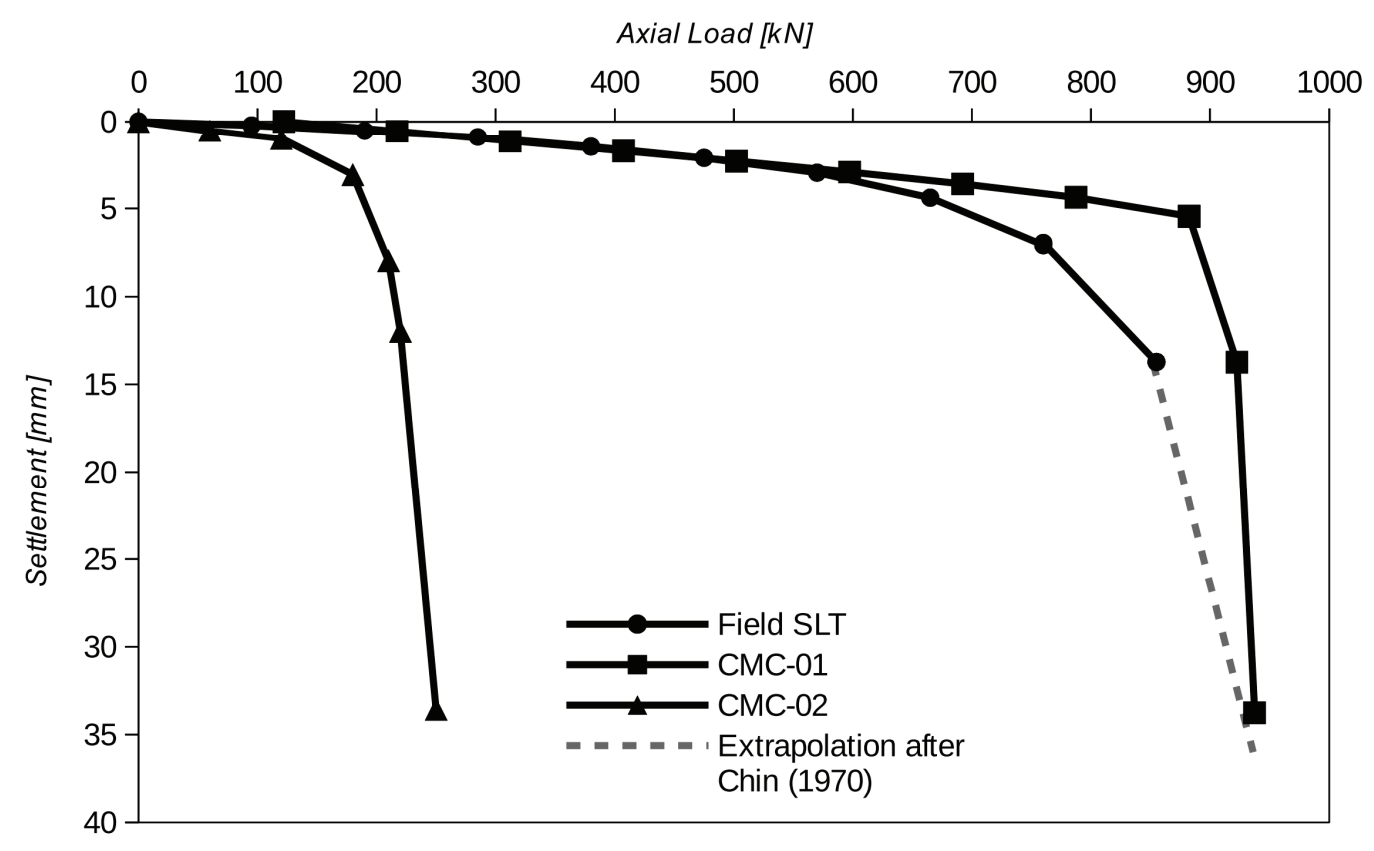

Fig. 12. Field Static load test versus numerical ones (CMC-1: "set-up" pile; CMC-2: "wish-in-place" pile)

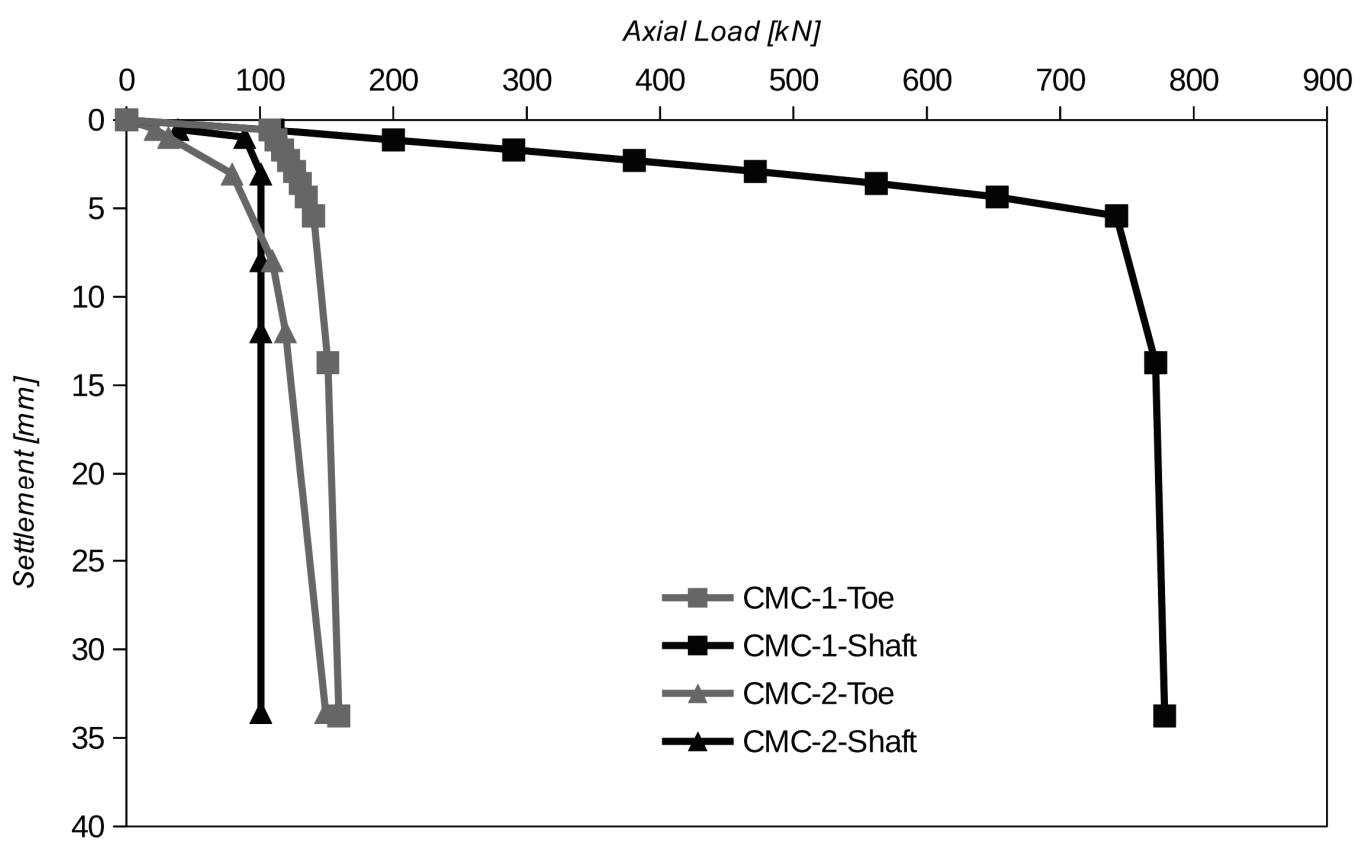

Fig. 13. Toe and shaft capacity obtained with CMC-1 and CMC-2 numerical models

effects on radial stress distribution the little changes in initially applied coefficient of friction can result in significant advances in pile shaft bearing capacity. In this paper, the interface angle has been assumed on literature databases and this choice allows for a good fit of the numerical Q-s curve to the field one. However, this may not be the rule and the interface modelling requires more attention.

\section{CONCLUSIONS}

The numerical analysis conducted has shown that installation effects have dominant influence on the total pile capacity, especially on the pile shaft resistance. The numerical model has been created in accordance with in-situ reference CMC pile and the 
numerical study results have been validated with field SLT results. Based on the analysis performed the following conclusions can be drawn:

- It has been found that pile base capacity is less influenced by installation process and the installation effects do not influence toe region, in general. However, the increase in radial effective stress after installation and following consolidation step is significant and this might be the fundamental reason for underestimation of the total pile capacity in "wish-in-place" pile.

- The UL model of "set-up" pile has been verified by field tests and the installation phase has been independently tested with CEL formulation. UL FEM and CEL models show similarity in total radial stress and in pushing force distribution although the different numerical formulations and stress approaches have been used in both models (effective stress approach in UL FEM and total stress approach in CEL).

- It has been shown that consideration of installation process in the pile numerical modelling can be important part of design process which can be helpful in more precise calculation of total bearing capacity.

- The possible influence of proper interface modelling on pile shaft capacity has been pointed out and the future studies in this field should be undertaken.

Summing up, the current advances in numerical and computational mechanics allows the installation effects to be incorporated in numerical modelling of displacement piles, which has a significant effect on total pile bearing capacity and the pile shaft capacity in particular.

\section{ACKNOWLEDGEMENTS}

The authors would like to thank Menard Polska for providing geotechnical documentation and SLTs results for Poznań Łacina Commercial Centre. The research is supported by the National Centre for Research and Development grant PBS3/B2/18/2015. The calculations were carried out at the Academic Computer Centre in Gdańsk (CI TASK).

\section{REFERENCES}

[1] AtKInson J., The mechanics of soils and foundations, CRC Press, 2007.

[2] Bienen B., QIu G., PuCKer T., CPT correlation developed from numerical analysis to predict jack-up foundation penetration into sand overlying clay, Ocean Engineering, 2015, 108, 216-226, DOI: 10.1016/j.oceaneng.2015.08.009.

[3] Chen X., Zhang J., XiAo Y., Li J., Effect of roughness on shear behavior of red clay-concrete interface in large-scale direct shear tests, Canadian Geotechnical Journal, 2015, 52(8), 1122-1135, DOI: 10.1139/cgj-2014-0399.
[4] CHIN F.K., Estimation of the ultimate load of piles not carried to failure, In 2nd Southeast Asia Conference on Soil Engineering, 11-15 June 1970, 81-90. Singapore: Southeast Asian Society of Soil Engineering.

[5] Dassault Systémes, 2013. Abaqus 6.13 Analysis User's Guide, Dassault Systèmes.

[6] Doherty P., GAvin K., Pile aging in cohesive soils, Journal of Geotechnical and Geoenvironmental Engineering, 2013, 139(9), 1620-1624, DOI: 10.1061/(ASCE)GT.1943-5606.0000884.

[7] Grabe J., Henke S., Pucker T., Hamann T., CEL: simulations for soil plugging, screwed pile installation and deep vibration compaction, [in:] M.A. Hicks, J. Dijkstra, M. Lloret-Cabot, M. Karstunen (eds.), International Conference on Installation Effects in Geotechnical Engineering, (pp. 118-127). London: Taylor and Francis Group, 2013, DOI: 10.1201/b13890-19.

[8] HAMANN T., QIU G., GRABE J., Application of a Coupled Eulerian-Lagrangian approach on pile installation problems under partially drained conditions, Computers and Geotechnics, 2015, 63, 279-290, DOI: 10.1016/j.compgeo.2014.10.006.

[9] Jiangtao Y., Centrifuge and Numerical Modelling of Sand Compaction Pile Installation, Phd Thesis, National University of Singapore, Singapore. 2009.

[10] Komurka V.E., Wagner A.B., Edil T.B., A Review of Pile Set-Up, Proc., 51st Annual Geotechnical Engineering Conference 2003

[11] Konkol J., Numerical estimation of the pile toe and shaft unit resistances during the installation process in sands, Studia Geotechnica et Mechanica, 2015, 37(1), 37-44, DOI: 10.1515/sgem-2015-0005

[12] KONKOL J., BAŁACHOWSKI L., Large deformation finite element analysis of undrained pile installation, Studia Geotechnica et Mechanica, 2016, 38(1), 45-54, DOI: 10.1515/sgem-2016-0005.

[13] LARISCH M., Behaviour of stiff, fine-grained soil during the installation of screw auger displacement piles, Phd Thesis. University of Queensland, Queensland, Australia 2014.

[14] Long J., Kerrigan J., Wysockey M., Measured time effects for axial capacity of driven piling, Transportation Research Record: Journal of the Transportation Research Board, 1999, (1663), 8-15, DOI: 10.3141/1663-02.

[15] Mabsout M.E., Tassoulas J.L., A finite element model for the simulation of pile driving, International Journal for numerical methods in Engineering, 1994, 37(2), 257-278, DOI: 10.1002/nme.1620370206.

[16] NoH W.F., CEL: a time-dependent, two-space-dimensional, coupled Eulerian-Lagrangian code, Lawrence Radiation Lab., Univ. of California, Livermore 1963.

[17] QIU G., Henke S., Grabe J., Application of a Coupled Eulerian-Lagrangian approach on geomechanical problems involving large deformations, Computers and Geotechnics, 2911, 38(1), 30-39, DOI: 10.1016/j.compgeo.2010.09.002.

[18] Randolph M.F., Carter J.P., Wroth C.P., Driven piles in clay-the effects of installation and subsequent consolidation, Geotechnique, 1979, 29(4), 361-393, DOI: 10.1680/ geot.1979.29.4.361.

[19] SCHMERTMANN J.H., The mechanical aging of soils, Journal of Geotechnical Engineering, 1991, 117(9), 1288-1330, DOI: 10.1061/(ASCE)0733-9410(1991)117:9(1288).

[20] Tomlinson M., Woodward J., Pile design and construction practice, CRC Press 2014.

[21] Vardanega P.J., Bolton M.D., Stiffness of clays and silts: Normalizing shear modulus and shear strain, Journal of Geotechnical and Geoenvironmental Engineering, 2013, 139(9), 1575-1589, DOI: 10.1061/(ASCE)GT.1943-5606.0000887.

[22] Wroth C.P., The interpretation of in situ soil tests, Geotechnique, 1984, 34(4), 449-489, DOI: 10.1680/geot.1984.34.4.449. 